\title{
Loss to follow-up in a community clinic in South Africa - roles of gender, pregnancy and $\mathrm{CD} 4$ count
}

\author{
Bingxia Wang, Elena Losina, Ruth Stark, Alison Munro, Rochelle P Walensky, Marisa Wilke, Des Martin, Zhigang Lu,
} Kenneth A Freedberg, Robin Wood

Background. Faith-based organisations have expanded antiretroviral therapy (ART) in community clinics across South Africa. Loss to follow-up (LTFU), however, limits the potential individual and population treatment benefits and optimal care.

Objective. To identify patient characteristics associated with LTFU 6 months after starting ART in a large community clinic.

Methods. Patients initiating ART between April 2004 and October 2006 in one South African Catholic Bishops' Conference HIV treatment clinic who had at least one follow-up visit were included and routinely monitored every 6 months after ART initiation. Standardised instruments were used to collect data. Rates of LTFU over time were estimated by the Kaplan-Meier method. The Cox proportional hazard regression examined the impact of age, baseline CD4 count, baseline HIV RNA, gender and pregnancy status on LTFU.

Results. Data from 925 patients (age $>14$ years, median age 36 years, $70 \%$ female, of whom $16 \%$ were pregnant) were included: 51
(6\%) were lost to follow-up 6 months after ART initiation. Younger age ( $\leq 30$ years) (hazard ratio (HR) $2.14,95 \%$ confidence interval (CI) 1.05 - 4.38) and pregnancy for women (HR 3.75, 95\% CI 1.53 - 9.16) were significantly associated with higher LTFU rates. When stratified by baseline CD4 count, gender and pregnancy status, pregnant women with lower baseline CD4 counts $(\leq 200$ cells/ $\mu$ ) had 6.06 times the hazard (95\% CI $2.20-16.71)$ of LTFU at 6 months compared with men.

Conclusions. HIV-infected pregnant women initiating ART were significantly more likely to be lost to follow-up in a community clinic in South Africa. Urgent interventions to successfully retain pregnant women in care are needed.

S Afr Med J 2011;101:253-257.
Division of General Medicine, Department of Medicine, Massachusetts General Hospital, Boston, Mass.; Harvard University Center for AIDS Research (CFAR), Harvard Medical School, USA

Bingxia Wang, $\mathrm{PhD}$

CFAR, Harvard Medical School; Departments of Orthopedic Surgery, Brigham and Women's Hospital; Department of Biostatistics, Boston University School of Public Health, Boston, USA

Elena Losina, $\mathrm{PhD}$

Catholic Relief Services South Africa

Ruth Stark, PhD

Marisa Wilke, MCur

Southern African Catholic Bishops' Conference

Sr. Alison Munro, MA, MTh

Divisions of General Medicine and Infectious Diseases, Department of Medicine, Massachusetts General Hospital; CFAR, Harvard Medical School; Division of Infectious Diseases, Brigham and Women's Hospital, Boston

Rochelle P Walensky, MD, MPH

Department of Clinical Virology, University of Pretoria

Des Martin, MB BCh, MMed (Virol), FCPath (SA), DTM\&H, DPH

Division of General Medicine, Department of Medicine, Massachusetts General Hospital

Zhigang Lu, MD

Divisions of General Medicine and Infectious Diseases, Department of Medicine, Mas sachusetts General Hospital; CFAR, Harvard Medical School

Kenneth A Freedberg, MD, MSc

Desmond Tutu HIV Centre, Institute for Infectious Disease and Molecular Medicine, and Department of Medicine, University of Cape Town

Robin Wood, MD
South Africa has an estimated 5.7 million individuals infected with HIV, 350000 people died from AIDS-related complications in 2007, ${ }^{1,2}$ and about one-third of all pregnant women are HIV infected., The growth of the HIV epidemic has led to rapid expansion of HIV care and treatment. ${ }^{2}$

Many non-governmental organisations (NGOs) operate mentoring and support programmes for HIV-infected people in resourcelimited countries. ${ }^{5,6}$ In South Africa, faith-based organisations play a significant and expanding role in providing HIV care and access to antiretroviral therapy (ART) ${ }^{7,8}$ One of the largest of these programmes is jointly run by the Southern African Catholic Bishops' Conference (SACBC) and the Catholic Relief Services (CRS) and is funded by the US President's Emergency Plan for AIDS Relief (PEPFAR). ${ }^{9}$ The ART treatment programme operated by the SACBC and the CRS is spread widely across South Africa and is involved in locally based HIV responses in many South African communities. ${ }^{10}$

Evaluating the outcomes of patients initiating ART is critical for ART treatment programmes. However, outcomes are generally based only on patients who remain in care. ${ }^{11}$ High rates of loss to followup (LTFU) diminish treatment options and substantially limit the effectiveness of ART strategies. ${ }^{12,13}$ Furthermore, evidence suggests heterogeneity in rates of LTFU for men and women. ${ }^{14}$ Pregnancy may also contribute to higher rates of suboptimal retention in care. ${ }^{15}$ There is therefore an urgent need for a better understanding of LTFU in patients who initiate ART. We aimed to identify the impact of gender, pregnancy status and CD4 count on LTFU 6 months after ART initiation in one of the largest SACBC/CRS treatment programmes in South Africa.

\section{Methods Setting}

This study was conducted in Tapologo, one of the SACBC/CRS HIV treatment clinics that work with mine worker communities in the greater Rustenburg area of the North West province of South Africa. ${ }^{16}$ Through a network of caregivers, Tapologo provides home-based care, 
local clinical consultation and support services to migrant workers and men and women in informal settlements around the mines. ${ }^{17}$ The clinic population comprises urban adults (age $>14$ years) in the mining community. They receive ART from home-based caregivers who are supported financially by the platinum mines, the SACBC and other partners. The clinic employs doctors, nurses, counsellors and adherence monitors. ${ }^{17}$ Treatment protocols closely follow South African National Department of Health (DOH) guidelines. ${ }^{18,19}$ Adherence education is given before and during ART. Tapologo clinic services offered for pregnant women include counselling and emotional support, HIV/AIDS education and awareness, positive living, and food security and nutrition. Clinical services include HIV testing, treatment of tuberculosis and other life-threatening diseases, general medical care, and treatment of sexually transmitted and opportunistic infections.

\section{Study sample}

The cohort included HIV-infected patients who either developed AIDS or had a CD4 count that met criteria for ART initiation based on DOH guidelines at that time $(\mathrm{CD} 4 \leq 200 / \mu \mathrm{l}) .{ }^{19}$ Patients initiating ART between January 2004 and October 2006 and eligible for at least one follow-up visit were included. After ART initiation patients were followed up every 6 months, with CD4 counts and HIV RNA tests done at each clinic visit.

\section{Data elements}

Standardised data reporting forms were used to collect data. Demographic characteristics at baseline included date of birth (or age) and sex. Clinical characteristics included WHO stage at enrollment, height, weight, pregnancy status for women, functional status and ART history. CD4 count and HIV RNA were measured at the initiation of ART and at each clinic visit. All records were maintained by the local site.

\section{Definition of outcomes}

The outcome for the study was defined as the proportion of LTFU in patients initiating ART. Two definitions for LTFU were considered: the clinic-based definition, used in the main analysis, was determined by the Tapologo-based provider as failure to return for a scheduled consultation or medication pick-up within 6 months after ART initiation ${ }^{13}$ and the data-based definition was a lack of recorded information in the database on a patient returning for a 6-month visit. LTFU was determined according to the data-based definition if no information was recorded for a patient with respect to the date of the 6-month follow-up visit and there was no laboratory testing (CD4 or HIV RNA tests) within 6 months of ART initiation. The data-based definition was used in sensitivity analyses.

\section{Statistical analysis}

Data available on 30 April 2007 on all patients with at least 6 months of follow-up time were analysed. At 6 months after ART initiation, patients who had unknown drop-out status, had ART discontinued by their physician, had voluntarily discontinued treatment, had been transferred out of the programme or had died were censored. Study time for each patient was therefore calculated from the date of ART initiation until the date of drop-out, if known, or the date 6 months after ART initiation, if the date of drop-out was unknown. For patients lost to follow-up at 6 months after ART initiation, study time was calculated from the date of ART initiation until the date of LTFU. Kaplan-Meier estimates were used to analyse the cumulative probability of LTFU. The log-rank test examined differences in LTFU rates within patient subgroups.
Demographic and clinical variables were grouped as categorical: age ( $\leq 30,31-40,>40$ years), gender and pregnancy status (pregnant women, non-pregnant women, men), baseline CD4 count $(\leq 200 / \mu l$, $>200 / \mu \mathrm{l})$, and baseline HIV RNA $(\leq 100000$ copies $/ \mathrm{ml},>100000$ copies $/ \mathrm{ml})$. To determine the effect of baseline CD4, gender and pregnancy status on LTFU, we stratified pregnancy status by baseline CD4 count for women $(>200 / \mu \mathrm{l}$ and $\leq 200 / \mu \mathrm{l})$, but not for men as they had no LTFU events with baseline CD4 $>200 / \mu l$. Such stratification resulted in a variable with five categories: pregnant women with CD4 $\leq 200 / \mu$ l, pregnant women with CD4 $>200 / \mu \mathrm{l}$, non-pregnant women with $\mathrm{CD} 4 \leq 200 / \mu$ l, non-pregnant women with CD4 $>200 / \mu l$, and men. For individual and stratified variables, hazard ratios (HRs) with corresponding 95\% confidence intervals (CIs) for LTFU were analysed through Cox proportional hazard regression. Two-sided $p$-values $<0.05$ were considered statistically significant. Analyses were performed using SAS software (version 9.1 or higher, SAS Institute Inc., Cary, NC, USA).

\section{Results}

\section{Cohort characteristics}

Among adult patients (age $>14$ years) accessing SACBC/CRS clinics in Tapologo, 925 met the criteria for analysis. Their median age was 36 years (interquartile range (IQR) 29 - 44), and 645 (70\%) were female, of whom $16 \%$ were pregnant. At ART initiation, the median CD4 count was 111/ $\mu \mathrm{l}$ (IQR $41-214 / \mu \mathrm{l}$ ) and the median HIV RNA $4.9 \log _{10}$ copies/ml (IQR 4.4 - 5.4). On initiating ART, approximately $45 \%$ of patients had a baseline HIV RNA $>100000$ copies $/ \mathrm{ml} ; 72 \%$ of patients and one-third of pregnant women had a baseline CD4 count $\leq 200 / \mu \mathrm{l}$ (Table I).

\section{Reasons for discontinuing ART}

Of the patients 322 (35\%) discontinued ART within 6 months of ART initiation. Among them 37 (11\%) were discontinued by physician recommendation, 21 (7\%) transferred out of the Tapologo programme, 213 (66\%) died, and 51 (16\%) were lost to follow-up (the clinic-based definition). Patients with unknown drop-out status were considered as remaining in care and were subsequently censored 6 months after ART initiation.

\section{Association between patient characteristics and LTFU 6 months after ART initiation}

Kaplan-Meier analysis indicated that during the study the cumulative probability of LTFU 6 months after ART initiation was 6\% (95\% CI $4-7 \%$ ) for the cohort. Log-rank tests showed that the cumulative probability of LTFU was significantly different across the sex and pregnancy subgroups $(p=0.01)$. The cumulative probability of LTFU 6 months after ART initiation was 12\% (95\% CI 5 - 18\%) for pregnant women, 6\% (95\% CI 4 - 8\%) for non-pregnant women, and 3\% (95\% CI 1 - 5\%) for men (Table II).

Cox proportional hazard regression analyses quantified the effect of all characteristics on LTFU (Table II). Younger age ( $\leq 30$ years) (HR 2.14, 95\% CI 1.05 - 4.38), and pregnancy for women (HR 3.75, 95\% CI 1.53 - 9.16) were significantly related to higher LTFU rates at 6 months from ART initiation. However, in terms of the overall effect, gender and pregnancy status was the only factor showing a statistically significant association with LTFU $(p=0.01)$.

Although we did not find an overall association between baseline CD4 and LTFU at 6 months, there was a significant impact on LTFU related to pregnancy in the lower CD4 stratum. If baseline CD4 was $\leq 200 / \mu l$, pregnant women had 3.62 times of hazard of LTFU compared with non-pregnant women (95\% CI 1.52 - 8.62). To examine this joint effect, gender and pregnancy status was further stratified by baseline 
Table I. Baseline characteristics of HIV-infected patients initiating ART in the Tapologo community clinic in South Africa

\begin{tabular}{|c|c|c|c|c|}
\hline Characteristics & $\begin{array}{c}\text { Men } \\
(N=280)\end{array}$ & $\begin{array}{l}\text { Non-pregnant women } \\
\qquad(N=541)\end{array}$ & $\begin{array}{l}\text { Pregnant women } \\
\qquad(N=104)\end{array}$ & $\begin{array}{c}\text { Total } \\
(N=925)\end{array}$ \\
\hline \multicolumn{5}{|c|}{ Age (yrs) $(N(\%))$} \\
\hline$\leq 30$ & $39(14)$ & $157(29)$ & $73(70)$ & $269(29)$ \\
\hline $31-40$ & $93(33)$ & $209(39)$ & $29(28)$ & $331(36)$ \\
\hline$>40$ & $148(53)$ & $175(32)$ & $2(2)$ & $325(35)$ \\
\hline \multicolumn{5}{|c|}{$\begin{array}{l}\text { Baseline HIV RNA } \\
\text { (copies/ml) }(N(\%))\end{array}$} \\
\hline$\leq 100000$ & $136(49)$ & $284(53)$ & $87(84)$ & $507(55)$ \\
\hline$>100000$ & $143(51)$ & $252(47)$ & $17(16)$ & $412(45)$ \\
\hline \multicolumn{5}{|c|}{$\begin{array}{l}\text { Baseline CD4 count } \\
(\text { cells/ } \mu \mathrm{l})(N(\%))\end{array}$} \\
\hline$\leq 200$ & $220(79)$ & $411(76)$ & $35(34)$ & $666(72)$ \\
\hline$>200$ & $58(21)$ & $125(23)$ & $69(66)$ & $252(27)$ \\
\hline
\end{tabular}

Table II. Association between demographics, clinical characteristics and rates of loss to follow-up at 6 months (clinic-based definition)

\begin{tabular}{|c|c|c|c|c|}
\hline & $\begin{array}{l}\text { Total } \\
(N(\%))\end{array}$ & $\begin{array}{l}\text { LTFU } \\
(N(\%))^{*}\end{array}$ & $\begin{array}{l}\text { HR } \\
(95 \% \mathrm{CI})\end{array}$ & $p$-value \\
\hline Total & $925(100)$ & 51 & - & - \\
\hline Age (yrs) & & & & 0.11 \\
\hline$\leq 30$ & $269(29)$ & $20(7)$ & $2.14(1.05-4.38)$ & \\
\hline $31-40$ & $331(36)$ & $19(6)$ & $1.53(0.74-3.16)$ & \\
\hline$>40$ & $325(35)$ & $12(4)$ & 1.00 & \\
\hline $\begin{array}{l}\text { Baseline HIV RNA } \\
\text { (copies/ml) }\end{array}$ & & & & 0.17 \\
\hline$\leq 100000$ & $507(55)$ & $35(7)$ & $1.51(0.83-2.72)$ & \\
\hline$>100000$ & $416(45)$ & $16(4)$ & 1.00 & \\
\hline $\begin{array}{l}\text { Baseline CD4 count } \\
\text { (cells/ } / \mu \mathrm{l})\end{array}$ & & & & 0.73 \\
\hline$\leq 200$ & $666(72)$ & $34(5)$ & $0.90(0.50-1.62)$ & \\
\hline$>200$ & $252(27)$ & $17(7)$ & 1.00 & \\
\hline $\begin{array}{l}\text { Gender and pregnancy } \\
\text { status }\end{array}$ & & & & 0.01 \\
\hline Pregnant women & $104(11)$ & $12(12)$ & $3.75(1.53-9.16)$ & \\
\hline Non-pregnant women & $541(58)$ & $31(6)$ & $1.98(0.91-4.30)$ & \\
\hline Men & $280(30)$ & $8(3)$ & 1.00 & \\
\hline
\end{tabular}

CD4, and proportional hazard regression analyses were conducted. Pregnant women with baseline CD4 $\leq 200 / \mu$ l had the highest risk of LTFU 6 months after ART initiation (HR 6.06, 95\% CI 2.20 - 16.71), followed by non-pregnant women with baseline CD4 $>200 / \mu \mathrm{l}(\mathrm{HR}$ 2.91, 95\% CI 1.19 - 7.11) and pregnant women with baseline CD4 $>200 / \mu \mathrm{l}$ (HR 2.44, 95\% CI 0.80 - 7.46) (Table III, Fig. 1).

\section{Sensitivity analysis: the impact of the definition of LTFU}

To detect the impact of alternative definitions of LTFU, we conducted sensitivity analyses using the data-based definition of LTFU; 95 patients $(10 \%)$ were lost to follow-up 6 months after initiating ART. Proportional hazard regression analysis showed that pregnant 
Table III. Cox proportional hazard regression of LTFU at 6 months on baseline CD4 and sex and pregnancy status for both the clinic-based and the data-based definitions

\begin{tabular}{|c|c|c|c|c|}
\hline & \multicolumn{2}{|c|}{$\begin{array}{l}\text { Clinic-based definition } \\
\qquad(p=0.01)\end{array}$} & \multicolumn{2}{|c|}{$\begin{array}{l}\text { Data-based definition } \\
\qquad(p=0.02)\end{array}$} \\
\hline & $\begin{array}{c}\text { LTFU } \\
(N(\%))^{*}\end{array}$ & $\begin{array}{c}\mathrm{HR} \\
(95 \% \mathrm{CI})\end{array}$ & $\begin{array}{c}\text { LTFU } \\
(N(\%))^{*}\end{array}$ & $\begin{array}{c}\mathrm{HR} \\
(95 \% \mathrm{CI})\end{array}$ \\
\hline Total & 51 & - & 95 & - \\
\hline \multicolumn{5}{|l|}{$\begin{array}{l}\text { Baseline CD4 (cells/ } \mu \mathrm{l}) \text {, gender } \\
\text { and pregnancy status }\end{array}$} \\
\hline Pregnant women, CD $4 \leq 200$ & $7(20)$ & $6.06(2.20-16.71)$ & $7(20)$ & $2.67(1.12-6.35)$ \\
\hline Pregnant women, CD $4>200$ & $5(7)$ & $2.44(0.80-7.46)$ & $11(16)$ & $2.40(1.14-5.05)$ \\
\hline $\begin{array}{l}\text { Non-pregnant women, CD4 } \\
\leq 200\end{array}$ & $19(5)$ & $1.66(0.73-3.80)$ & $36(9)$ & $1.37(0.79-2.39)$ \\
\hline \multicolumn{4}{|l|}{$>200$} & $2.29(1.24-4.24)$ \\
\hline Men & $8(3)$ & 1.00 & $19(7)$ & 1.00 \\
\hline $\begin{array}{l}\text { Clinic-based definition = failure to return } \\
\text { least } 6 \text { months; LTFU = loss to follow-up; } \\
\star \% \text { refers to the proportion of those LTFU }\end{array}$ & $\begin{array}{l}\text { ltation or } \mathrm{m} \\
\mathrm{I}=\text { confiden } \\
\text { in each grou }\end{array}$ & up within 6 months after & data-based d & any visit information fo \\
\hline
\end{tabular}

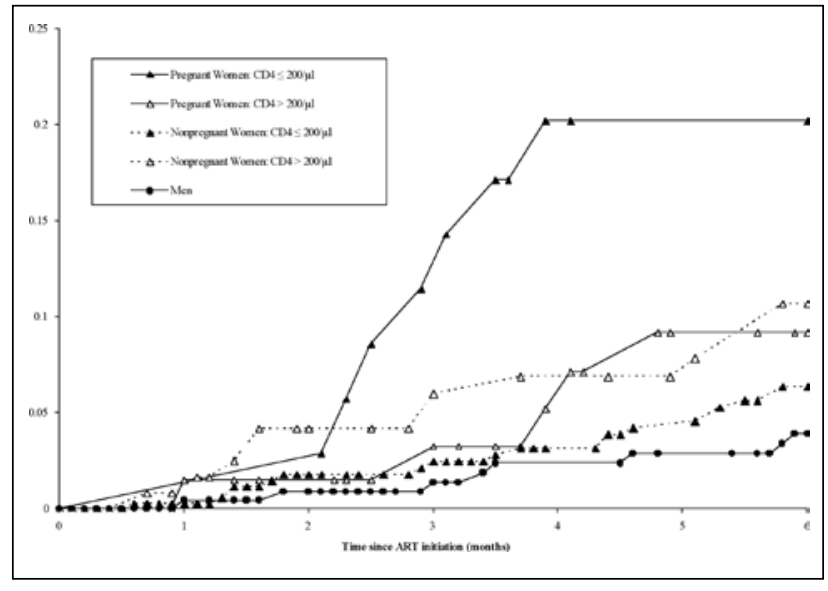

Fig. 1. Cumulative probability of loss to follow-up 6 months from ART initiation, stratified by baseline CD4, gender and pregnancy status. Differences among all groups are highly significant by Kaplan-Meier analysis.

women with baseline CD4 $\leq 200 / \mu$ l had the highest risk of LTFU 6 months after ART initiation (HR 2.67, 95\% CI 1.12 - 6.35), followed by pregnant women with baseline CD $4>200 / \mu \mathrm{l}$ (HR 2.40, 95\% CI 1.14 - 5.05) and non-pregnant women with baseline CD4 $>200 / \mu \mathrm{l}$ (HR 2.29, 95\% CI 1.24 - 4.24) (Table III). The overall joint effects of baseline CD4, gender and pregnancy status on LTFU were similar for clinic- and data-based definitions of LTFU.

\section{Discussion}

In the community-based cohort of 925 adults eligible for ART, we analysed patient characteristics associated with LTFU 6 months after ART initiation. Gender and pregnancy status was significantly related to LTFU, and pregnant women had the highest risk of LTFU.

In ART programmes in resource-limited settings, LTFU is a major problem for optimal care of HIV-infected individuals. ${ }^{13,15,20}$ Studies describing associations with LTFU in ART treatment programmes in South Africa have used chart reviews to investigate patient characteristics predicting LTFU in large ART treatment programmes in public hospitals. Causes of LTFU included financial difficulty, lack of patient knowledge that ART needs to be lifelong, hospitalisation or illness, medication toxicity, CD4 count increase, and death. ${ }^{20,21}$ Little work has focused on the relationship between LTFU and gender and pregnancy. ${ }^{15}$ With an HIV prevalence among pregnant women in South Africa of 20 - 30\%, further understanding of LTFU among pregnant women on ART could help improve their retention in care and may also decrease risk of mother-to-child HIV transmission. ${ }^{8,15,22}$ We identified characteristics including gender and pregnancy status associated with LTFU in patients who began ART in the Tapologo programme, one of SACBC/CRS HIV care and treatment clinics in North West province, South Africa.

Although there was insufficient statistical evidence to support an association between baseline clinical characteristics (HIV RNA or CD4 count) and LTFU 6 months after ART initiation, the distributions of these clinical characteristics in pregnant women differed from non-pregnant women and men. The stratified analysis in baseline CD4 $\leq 200 / \mu \mathrm{l}$ also showed that pregnant women were more likely to be lost to care than non-pregnant women. This evidence indicates the possible joint effects of clinical characteristics, gender and pregnancy status. To detect the joint effects of baseline $\mathrm{CD} 4$, gender and pregnancy status, we stratified pregnancy status by baseline CD4 count for women because there were no LTFU events for men with high baseline CD4 counts based on the preliminary results. A Cox proportional hazard model quantified the joint effects on LTFU. Sensitivity analyses using a second standardised (data-based) definition of LTFU examined the impact of different definitions on LTFU. Although HIV-infected non-pregnant women who initiated ART and had higher CD4 counts were significantly more likely to be lost to care, pregnant women initiating ART at all stages of HIV disease were at substantial risk of LTFU, with its attendant risk of developing an AIDS-defining illness or of death. Our data suggested that the relationship between CD4 count and LTFU among women was modified by pregnancy status. Women with high CD4 counts were at similar risk of LTFU regardless of pregnancy 
status. In contrast, pregnant women with low CD4 counts were at increased risk for LTFU compared with non-pregnant women. This discrepancy may be due to the increased burden of health and social conditions, including pregnancy, that HIV-infected women face. The stigma associated with HIV disease may explain the higher rates of LTFU among the women with higher CD4.

This study had several limitations. First, the reasons why pregnant women stopped treatment were not available. In mining communities in South Africa, many women live in shacks with no stable income and no stable partner to support them. Many have no access to potable water, decent sanitation or adequate nutrition. Although this ART programme was a local clinic that provided community-based care at no cost, pregnancy is a financial burden for women and their families. The higher proportion of LTFU among pregnant women may be due to lack of financial support and increased prenatal care costs. Since many women around the mines are from other parts of South Africa or other countries, physical relocation may be a risk factor for failure to return for further visits. Another explanation of LTFU among pregnant women may be that some of them may transfer out of the SACBC/CRS ART treatment programmes to maternal care facilities or to hospitals without informing local clinic staff. To ensure that pregnant women receive timely treatment and care for HIV during pregnancy and the postpartum period, improved linkage with other ARV centres and maternal services via data sharing to systematically monitor patients is critical. Patient records were maintained by the local site; however, there were no data for about $10 \%$ of the Tapologo patients. To perform this analysis, we conservatively assumed that patients with missing current treatment status were in care, which probably underestimated the rates of LTFU. ${ }^{11}$ Since this study was limited to one clinic in the programmes of the SACBC/CRS it may not be representative of the population of persons with HIV initiating ART in South Africa.

This was the first systematic study of LTFU in the programmes of the SACBC and CRS in South Africa. Pregnant women with HIV disease initiating ART were at the greatest risk of being lost to followup. To ensure the best outcomes for HIV-infected women, and to prevent HIV transmission from mother to child, interventions to successfully retain pregnant women in care are urgently needed.

The authors wish to thank Lauren Uhler, Jennifer Chu and Ji-Eun Park for their invaluable support and expert technical assistance.

The paper was presented in part at the 15th Conference on Retroviruses and Opportunistic Infections, 3 - 6 February 2008, Boston, MA, USA (abstract 839).
Research ethics committee approval. The research was approved by the Research Ethics Committee of the University of Cape Town, South Africa (Rec. Ref: 169/2007).

Conflict of interest. The authors declare no conflict of interest.

\section{References}

1. Joint United Nations Programme on HIV/AIDS. 2008 Report on the Global AIDS Epidemic. Geneva: UNAIDS, 2008.

US President's Emergency Plan for AIDS Relief. Celebrating Life: The US President's Emergency Plan for AIDS Relief 2009 Annual Report to Congress, 2009. http://www.pepfar.gov/documents/ organization/113878.pdf (accessed 22 November 2010).

3. National HIV and Syphilis Prevalence Survey South Africa. Pretoria: Department of Health, 2007.

4. World Health Organization. HIV/AIDS Epidemiological Surveillance Report for the WHO African Region 2007 Update. Geneva: World Health Organization, 2008.

5. Kelly JA, Somlai AM, Benotsch EG, et al. Programmes, resources, and needs of HIV-prevention Kelly JA, Somlai AM, Benotsch EG, et al. Programmes, resources, and needs of HIV-prevention
nongovernmental organizations (NGOs) in Africa, Central/Eastern Europe and Central Asia, Latin

America and the Caribbean. AIDS Care 2006;18:12-21.
6. Community home-based care in resource limited settings. World Health Organization, Geneva, 2002. 6. Community home-based care in resource limited settings. World Health Organization, Gen
http://www.who.int/hiv/pub/prev_care/isbn9241562137.pdf (accessed 22 November 2010).

7. Wolvaardt G, van Niftrik J, Beira B, Mapham W, Stander T. The role of private and other nongovernmental organisations in primary health care. In: Barron P, Roma-Reardon J, eds. South Africa Health Review 2008. Durban: Health Systems Trust, 2008.

8. Wood R. Large Scale Implementation of Antiretroviral Therapy: Early Results from Faith-based Clinics in South Africa. South Africa: South Africa Catholic Bishops Conference (SACBC) AIDS Office Publications, 2007

9. FY 2007 South Africa Partners. 2008. http://www.pepfar.gov/partners/103018.htm (accessed 22 November 2010).

10. Activities in Free State Province: Fiscal year 2009. 2009. http://southafrica.usembassy.gov/root/pdfs/ pepfar-pdfs3/free-statel1.pdf (accessed 22 November 2010).

11. Geng EH, Emenyonu N, Bwana MB, Glidden DV, Martin JN. Sampling-based approach to determining outcomes of patients lost to follow-up in antiretroviral therapy scale-up programs in Africa. JAMA 2008:300:506-507.

12. Bisson GP, Gaolathe T, Gross R, et al. Overestimates of survival after HAART: implications for global scale-up efforts. PLoS One 2008;3:e1725.

3. Rosen S, Fox MP, Gill CJ. Patient retention in antiretroviral therapy programs in sub-Saharan Africa: A systematic review. PLoS Med 2007;4(10):e298.

14. Ochieng V, Ochieng D, Sidle J, et al. Gender and loss-to follow-up (LTFU) from a large HIV treatmen program in Western Kenya. Presented at AIDS 2008 - XVII International AIDS Conference, 3 - 8 August 2008, Mexico City.

15. Kaplan R, Orrell C, Zwane E, Bekker LG, Wood R. Loss to follow-up and mortality among pregnan women referred to a community clinic for antiretroviral treatment. AIDS 2008;22:1679-1681.

16. Supporting the Tapologo Programme. Zahra Foundation, 2009. http://www.zahrahelps.org/tapologo. asp (accessed 22 November 2010).

17. Tapologo HIV/AIDS Programme. Implats, 2007. http://www.implats.co.za/cr/reports/2007/tapologo. htm (accessed 22 November 2010).

18. Scaling up antiretroviral therapy in resource-limited settings: Guidelines for a public health Scaling up antiretroviral therapy in resource-limited settings: Guidelines for a public health
approach. World Health Organization, Geneva, 2004. http://www.who.int/hiv/pub/prev_care/en/ arvrevision2003en.pdf (accessed 22 November 2010).

19. National Antiretroviral Treatment Guidelines: South African National Department of Health, 2004 http://www.doh.gov.za/docs/factsheets/guidelines/artguidelines04/index.html (accessed 22 November 2010)

20. Dalal R, MacPhail C, Mghayi M, et al. Characteristics and outcomes of adult patients lost to followup at an antiretroviral treatment clinic in Johannesburg, South Africa. J Acquir Immune Defic Synd 2008;47:101-107.

21. Maskew M, MacPhail P, Menezes C, Rubel D. Lost to follow-up: contributing factors and challenges in South African patients on antiretroviral therapy. S Afr Med J 2007;97:853-857.

22. Chigwedere P, Seage GR, Lee TH, Essex M. Efficacy of antiretroviral drugs in reducing mother-to-child transmission of HIV in Africa: a meta-analysis of published clinical trials. AIDS Res Hum Retroviruses 2008;24:827-837.

Accepted 9 November 2010. 